\title{
Associations of the SCD1 gene SNP with fatty acids composition of Holstein cows
}

\author{
Natalia Yu. Safina ${ }^{1, *}$, Shamil K. Shakirov ${ }^{2}$, Rustam Kh. Ravilov ${ }^{2}$ and Gazimzyan S. Sharafutdinov ${ }^{3}$ \\ ${ }^{1}$ N.E. Bauman Kazan State Academy of Veterinary Medicine, Kazan 420029, Russia \\ ${ }^{2}$ Tatar Scientific Research Institute of Agriculture - Subdivision of the Federal State Budgetary Institution of Science "Kazan Scientific \\ Center of Russia Academy of Sciences”, Kazan 420059, Russia \\ ${ }^{3}$ Kazan State Agrarian University, Kazan 420015, Russia
}

\begin{abstract}
The research presents the findings of DNA testing of allelic polymorphism by the PCR-RFLP method of the SCD1 gene and the relationship of genotypes with the milk fatty acid composition of Holstein cows of Tatarstan population. The research was conducted among 172 Holstein cows at the Integrated Agricultural Production Centre "Stud farm named after Lenin" in Atninsky district of the Republic of Tatarstan in 2017-2018. All genotypes of the SCD1 gene were identified through the research. The milk yield test showed that the maximum content of the mass fraction of fat was in animals with the TT genotype. The significant difference between the content of the mass fraction of fat in milk in individuals by the locus of the SCD1-Fsp4H I gene was: TT to CC $-0.32 \%(\mathrm{p}<0.05)$ and TT to TC $-0.40 \%(\mathrm{p}<0.01)$. The results of chromatography indicate the balance of the milk fatty acid composition of cows with the TT genotype and, as a consequence, its positive effect on the human body. Cows with a homozygous TT genotype are characterized by the optimum ratio of fatty acids in milk fat. The maximum value of the oxygen desaturation index is also observed in animals with the TT genotype by the SCD1 gene.
\end{abstract}

\section{Introduction}

At the present stage of agricultural development generally, and of livestock section particularly, targeted selection for the improvement of farm livestock productivity is impossible without molecular genetic testing of economic characters based on hereditary information.

The composition, processing and biological properties of milk are conditional on the breed, feeding conditions, lactation stage, etc. [1-3]. The main factors that determine the amount of fat content in milk are hereditary breed and individual characteristics of animals, and at the same time - the level and usefulness of feeding the cows [4]. Compared with other milk constituents, the fatty acid composition is most changeable. Milk fat usually consists of $50-70 \%$ saturated fatty acids, 20 to $40 \%$ monounsaturated fatty acids, and 1 to $5 \%$ polyunsaturated fatty acids. Palmitic $(21-33 \%)$ and stearic $(8-13 \%)$ acids have the highest specific weight from the sum of all unsaturated fatty acids in cow's milk. Oleic acid (20-32 \%) and a slightly smaller volume of palmitoleic acid (1.5-2.4 \%) - from monounsaturated fatty acids. Unsaturated fatty acids are rated as favorable. Data obtained by C. Han et al. (2013) indicate that the fatty acid composition has a deeper effect on human health than the amount of fat in the diet [5].

Relationships related to milk production and content of the mass fraction of fat (\%), yield of milk fat $(\mathrm{kg})$ and correlation relationships of milk yield and fat, as well as the ratio of certain fatty acids to each other are of particular interest [6].

Stearoyl-CoA desaturase (SCD) is an endoplasmic reticular enzyme responsible for the $\Delta 9$-fatty acid desaturation in lacteous gland, adipose, and other tissues by introducing a double bond at the $\Delta-9$ position in Acyl-CoA substrates [7, 8]. By the action of insulin in the cells of a living organism, the enzyme expression of stearoyl-CoA desaturase (SCD) converts C16:0 palmitic acid formed from glucose into C18:0 stearic unsaturated fatty acid. Then stearic acid is converted to C18:1 $\omega-9$ oleic monounsaturated fatty acid. Oleic metabolism is more efficient than palmitic one. This ensures maximum performance of mitochondria in the synthesis of ATP and the supply of energy substrates for all biological functions $[9,10]$. There is a correlation with the oxygen desaturation index value, which is the ratio of saturated acids and mono- and polyunsaturated fatty acids [10].

The SCD1 gene is localized on the 26th bovine chromosome [11], where some QTL responsible for fertility, fat content, milk yield, and other quantitative characters were also identified [12, 13]. This gene consists of 6 exons and 5 introns and contains 17,088 bps. SNP (C878T) in exon 5 causes the replacement of valine with alanine $(\mathrm{V} \rightarrow \mathrm{A})$ in the $\mathrm{SCD}$ peptide [14-17].

There are confirmed data on the association of this mutation forms with the fatty acid composition. C878Tpolymorphism of the SCD1 gene had a significant effect

* Corresponding author: natysafina@gmail.com 
$(\mathrm{p}<0.05)$ on the content of myristic, linoleic, $\gamma$ linolenic, $\alpha$-linolenic acids, conjugated linoleic acid (CLA) and the total content of $\omega-6$ fatty acids in the research of scientists [18].

The age, species and breed of the animal affect the expression and activity of the SCD1 gene, which specifically affects the concentration of monounsaturated fatty acids $[19,20]$.

\section{Materials and Methods}

The experiment took place at the premises of Integrated Agricultural Production Centre "Stud farm named after Lenin" of Atninsky district of the Republic of Tatarstan. 172 Holstein cows were selected for the research. During the experiment all animals were kept under equal environmental conditions on a standard diet, with proper care, with normal veterinary and technological attendance, in a farm that was safe from infectious and invasive diseases. The analysis of the qualitative milk composition of the studied group of animals (mass fraction of fat, mass fraction of protein) was carried out on the device "Clover-2M" in accordance with the manufacturer's instructions. Milk samples for this analysis were taken during control milking once a season (4 times per lactation) in $50 \mathrm{ml}$ test tubes (Axygen, USA).

The analysis of the fatty acid composition of milk fat was carried out according to data obtained by examining milk samples from the studied Holstein livestock on gas chromatograph "Clarus 500GC" (PerkinElmer, USA) as per GOST (National Standard) 32915-2014 [21].

172 samples of whole blood were taken from the tail vein of Holstein cows during the work for DNA testing of allelic polymorphism of genetic markers of economic characters of cattle. The biomaterial was collected in K-3 EDTA preservative tubes containing the EDTA anticoagulant (APEXLAB, China).

DNA purification from whole blood of cattle was carried out using a ready-made set of "Ampli Prime" DNA-Sorb-B (Next Bio, Russia) in accordance with the manufacturer's instruction. Primers with the following oligonucleotide sequence were used for the PCR:

F: 5' - ATGTATGGATACCGCCCTTATGAC - 3' R: 5' - TTCTGGCACGTAACCTAATACCCTAAGC - 3' [22].

Amplification of fragments was carried out on programmable thermocyclers "T-100 Thermal Cycler" and "My Cycler" (BIO RAD, USA) at the optimal temperature-time mode developed for the specified set of primers. Cleavage of the obtained PCR samples for the SCD1 gene was carried out with a reaction mixture with restriction endonuclease Fsp4H I (SibEnzyme, Russia), introduced with a final volume of $5 \mu$ l into test tubes with amplifications. The hydrolysis of the samples was carried out at a temperature of $37{ }^{\circ} \mathrm{C}$ for 16 hours. Visualization, video recording and documentation were carried out using a UV transilluminator and a Gel\&Doc system (BIO-RAD, USA). Identification of genotypes was determined by the detectable polymorphism of DNA sequences.

\section{Results and Discussion}

The 145 bp amplicon was obtained during the polymerase chain reaction. Subsequent sample treatment with endonuclease $F s p 4 H$ I and visualization of the results of RFLP showed that the group of 172 cows under study is represented by two alleles and three genotypes of the SCD1 gene and is a polymorphic population. The fragments that underwent electrophoretic separation, as seen in figure 8 , had the following dimensions: CC $-29,48$ and $68 \mathrm{bp}, \mathrm{TC}-29$, 48, 68 and 116 bp, TT -29 and 116 bp.

Research into milk production in terms of the SCD1 gene polymorphism as shown in Table 1 indicates the predominance of the mass fraction of fat in cows with the TT genotype over individuals with other genotypes.

Table 1. Association of the SCD1 C878T polymorphism and traits of dairy productivity of Holstein cows

\begin{tabular}{|c|c|c|c|}
\hline \multirow{2}{*}{ Indicator } & \multicolumn{3}{|c|}{ Genotype } \\
\hline & $C C(\mathrm{n}=67)$ & $T C(\mathrm{n}=73)$ & $T T(\mathbf{n}=32)$ \\
\hline $\begin{array}{l}\text { Milk yield for } \\
\text { lactation (305 } \\
\text { days), kg }\end{array}$ & $7052.8 \pm 140.2$ & $7027.1 \pm 133.6$ & $6920.9 \pm 238.0$ \\
\hline Fat, \% & $3.78 \pm 0.08 *$ & $3.70 \pm 0.06^{* *}$ & $4.10 \pm 0.13$ \\
\hline Protein, \% & $3.40 \pm 0.03$ & $3.35 \pm 0.03$ & $3.30 \pm 0.04$ \\
\hline
\end{tabular}

The significant difference between the content of the mass fraction of fat in milk between animals by the locus of the SCD1-Fsp4H I gene was TT to CC $-0.32 \%(\mathrm{p}<0.05)$ and TT to TC $-0.40 \%(\mathrm{p}<0.01)$. The same group of animals tended to have an advantage in milk fat yield: TT to $\mathrm{CC}-13.1 \mathrm{~kg}(4.6 \%)$ and $\mathrm{TT}$ to $\mathrm{TC}-23.8 \mathrm{~kg}$ $(8.4 \%)$.

In terms of milk yield and protein mass fraction, the best data were recorded in cows with a homozygous CC genotype. Pozovnikova M.V. et al. (2017) also noted a significant superiority in milk yield $(\mathrm{p}<0.01)$ and milk protein yield $(p<0.001)$ in these animals over their herd mates with the TC and TT genotypes in their work [23].

The research of the milk fatty acid composition of the livestock under study in terms of the SCD1 gene polymorphism showed that all experimental groups of cows have fatty acid content within acceptable limits, according to the code norms for edible fats and oils, for which there are no separate standards (CODEX STAN 19-1981, REV. 2-1999) and in the standard of the code for named animal fats (CODEX STAN 211-1999). Table 2 shows the average values of the fatty acid composition of cow's milk fat based on gas chromatography results.

According to our data the significant difference in the content of lauric (C12:0) saturated fatty acid in the milk of animals with the TC genotype and the milk of groups of individuals with homozygous CC and TT genotypes was $0.20 \%(\mathrm{p}<0.05)$ and $0.23 \%(\mathrm{p}<0.05)$, respectively.

The results obtained show that animals with the CC genotype of the SCD1 gene had a higher content of myristic (C14:0) saturated fatty acid. The significant difference in this indicator between CC-individuals and cows with the TT genotype was recorded at the level of 
$0.32 \%(\mathrm{p}<0.05)$. A high content of palmitic $(\mathrm{C} 16: 0)$ saturated fatty acid is also observed in the milk fat of animals with the CC and TC genotypes. The gap for this trait was $0.64 \%(\mathrm{p}<0.01)$ between animals with $\mathrm{CC}$ and TT genotypes, and $0.55 \%(\mathrm{p}<0.05)$ between animals with TC and TT genotypes.

Table 2. Effect of the SCD1 C878T polymorphism on the milk fatty acids composition

\begin{tabular}{|l|c|c|c|c|}
\hline \multirow{2}{*}{ Fatty acid } & \multicolumn{3}{|c|}{ SCD1 genotype } & \multirow{2}{*}{ Allowable content, \% } \\
\cline { 2 - 5 } & $C C(\mathrm{n}=67)$ & $T C(\mathrm{n}=73)$ & $T T(\mathrm{n}=32)$ & \\
\hline Lauric C12:0 & $3.34 \pm 0.06$ & $3.54 \pm 0.05^{*}$ & $3.31 \pm 0.08$ & $2.0-4.4$ \\
\hline Myristic C14:0 & $12.85 \pm 0.09^{*}$ & $12.61 \pm 0.09$ & $12.53 \pm 0.12$ & $8.0-13.0$ \\
\hline Myristoleic C14:1 cis-9 & $1.14 \pm 0.01$ & $1.15 \pm 0.01$ & $1.19 \pm 0.02^{*}$ & $0.6-1.5$ \\
\hline Palmitic C16:0 & $27.52 \pm 0.16^{* *}$ & $27.43 \pm 0.15^{*}$ & $26.88 \pm 0.18$ & $21.0-33.0$ \\
\hline Palmitoleic C16:1 cis-9 & $1.79 \pm 0.01$ & $1.81 \pm 0.01$ & $1.84 \pm 0.02^{*}$ & $1.5-2.4$ \\
\hline Stearic C18:0 & $8.50 \pm 0.16$ & $8.75 \pm 0.14$ & $8.63 \pm 0.17$ & $8.0-13.5$ \\
\hline Oleic C18:1 cis-9 & $21.00 \pm 0.23$ & $21.81 \pm 0.23$ & $23.06 \pm 0.24^{* * *}$ & $20.0-32.0$ \\
\hline Linoleic C18:2 (CLA) trans-11 & $2.84 \pm 0.04$ & $2.88 \pm 0.03$ & $2.99 \pm 0.05^{*}$ & $2.2-5.5$ \\
\hline Linolenic C18:3(CLA) cis-9, trans-11 & $0.40 \pm 0.01$ & $0.41 \pm 0.01$ & $0.41 \pm 0.02$ & $0-1.5$ \\
\hline
\end{tabular}

The TT genotype had a significant effect on the content of myristoleic (C14:1), palmitoleic (C16:1) and oleic $(\mathrm{C} 18: 1)$ polyunsaturated fatty acids and conjugated linoleic acid (C18:2). The mass fraction of the total number of fatty acids in the milk fat of cow's milk of TTindividuals significantly exceeded the indicators obtained during research of milk of cows with the $\mathrm{CC}$ genotype by $0.05 \%(\mathrm{p}<0.05)$ for myristoleic, $0.05 \%$ $(\mathrm{p}<0.05)$ for palmitoleic, $2.06 \%(\mathrm{p}<0.001)$ for oleic and $0.15 \%(\mathrm{p}<0.001)$ for conjugated linoleic fatty acids. In terms of the content of oleic polyunsaturated fatty acid, a significant difference was also noted between the groups of animals with TT and TC genotypes $-1.25 \%(\mathrm{p}<0.001)$. In terms of the content of conjugated linolenic (C18:3) polyunsaturated fatty acid, there were no significant differences between individuals with different genotypes of the SCD1 gene. Animals with the CC genotype of the SCD1 gene have a significant advantage in the content of unsaturated fatty acids in milk in the research conducted by K.B. Inostroza et al. (2013) [24].

Cows with a homozygous TT genotype are characterized by the optimum ratio of fatty acids in milk fat (Table 3).

Table 3. Effect of the SCD1 C878T polymorphism on milk fatty acid unsaturation indexes

\begin{tabular}{|l|c|c|c|c|}
\hline \multirow{2}{*}{ Fatty acid } & \multicolumn{3}{|c|}{ Genotype } & \multirow{2}{*}{ Fatty acids ratio } \\
\cline { 2 - 5 } & $C C(\mathrm{n}=67)$ & $T C(\mathrm{n}=73)$ & $T T(\mathrm{n}=32)$ & $5.8-14.5$ \\
\hline Palmitoleic / Lauric & $8.24 \pm 0.09^{* * *}$ & $7.75 \pm 0.08$ & $8.12 \pm 0.10^{* *}$ & $1.9-5.9$ \\
\hline Stearic / Lauric & $2.54 \pm 0.03$ & $2.47 \pm 0.02$ & $2.61 \pm 0.06^{*}$ & $1.6-3.6$ \\
\hline Oleic / Myristic & $1.63 \pm 0.03^{* * *}$ & $1.73 \pm 0.03^{*}$ & $1.84 \pm 0.04$ & $0.1-0.5$ \\
\hline Linoleic / Myristic & $0.22 \pm 0.01$ & $0.23 \pm 0.01$ & $0.24 \pm 0.01$ & $0.4-0.7$ \\
\hline Total index & $0.46 \pm 0.01$ & $0.47 \pm 0.01$ & $0.51 \pm 0.02^{*}$ & \\
\hline
\end{tabular}

$*-\mathrm{p}<0.05 ; * *-\mathrm{p}<0.01 ; * * *-\mathrm{p}<0.001$

These results indicate the balance of the milk fatty acid composition in these animals and, as a consequence, its positive effect on the human body. According to the findings, the favorable difference in the ratio of oleic/myristic fatty acids between animals with TT and $\mathrm{CC}$ genotypes was $0.21(\mathrm{p}<0.001)$, and between animals with TT and TC genotypes $-0.11(\mathrm{p}<0.05)$. The ratio of palmitic to lauric acids and stearic to lauric acids in individuals with TT and TC genotypes was 0.37 $(\mathrm{p}<0.01)$ and $0.14(\mathrm{p}<0.05)$, respectively.

The maximum value of the oxygen desaturation index is also observed in animals with the TT genotype by the SCD1 gene. The advantage for this indicator of the specified group of animals and individuals with the CC genotype was $0.05(\mathrm{p}<0.05)$, and of cows with a heterozygous TC genotype -0.04 .

\section{Conclusion}

As a result of our research, we obtained new knowledge on the biodiversity, genetic pattern and forms of associations of the stearoyl-CoA desaturase gene polymorphism with signs of milk production and the composition of fatty acids in the milk of Holstein cows of the Tatarstan population of cattle. Animals with the TT genotype of the SCD1 gene are characterized by an increased content of fat mass fraction in milk and an optimal fatty acid composition of milk. Therefore, when culling and selecting animals for marker-assisted selection (MAS) to improve the qualitative milk composition and butter-fat yielding capacity, attention should be paid to animals with a homozygous TT genotype of the stearoyl-CoA desaturase (SCD1) gene.

\section{Acknowledgments}

This research was supported by FASO Russia project AAAA-A18-118031390148-1.

\section{References}

1. T.M. Akhmetov, S.V. Tjulkin, O.G. Zaripov, E.F. Valiullina, R.R. Vafin, Actual Quest. of Veter. Biology J. 1(1), 20-23 (2009) 
2. S.N. Alexandrov, L.I. Podobed, T.T. Kosova, V.L. Dudinsky, Theory and practice of profitable milk production (Kiev, 2011)

3. M.V. Votoropina, Sci. J. of the Kuban State Agrar. Univer. 97, 868-894 (2014)

4. E.O. Krupin, Sh.K. Shakirov, F.S. Gibadullina, M.Sh. Tagirov, M.G. Nurtdinov, N.N. Khazipov, S.I. Churin, Fats in feeding highly productive cows (Kazan, 2013)

5. C. Han, M. Vinsky, N. Aldai et al., Meat Sci. 93, 429-436 (2013)

6. E. Samková, J. Špička, M. Pešek, T. Pelikánová, O. Hanuš, South African J. of Animal Sci. 42(2), 83-100 (2012). Retrieved from: http://dx.doi.org/10.4314/sajas.v42i2.1

7. P.C. Garnsworthy, S. Feng, A.L. Lock, M.D. Royal, Dairy Sci. 93, 1743-1748 (2010)

8. H. Kulig, I. Kowalewska-Łuczak, K. Zukowski, M. Kunicka, Acta Scientiarium Polonorum, Zootechn. 12(1), 41-48 (2013)

9. J. Colman, K.-G. Rem, Visual biochemistry (Moscow, 2000)

10. V.N. Titov, Clin. Lab. Diagnost. 4, 27-38 (2014)

11. E.M. Campbell, D.S. Gallagher, S.K. Davis et al., J. Animal Sci. 79, 1954-1995 (2001)

12. J.K. Höglund, B. Guldbrandtsen, G. Su, B. Thomsen, M.S. Lund, J. of Dairy Sci. 92, 2136-2143 (2009) DOI: $10.3168 /$ jds.2008-1104

13. C.A. Morris, C.D. Bottema, N.G. Cullen, S.M. Hickey, A.K. Esmailizadeh, B.D. Siebert, W.S. Pitchford, Animal Genet. 41, 589-596 (2010)
14. L. Bernard, C. Leroux, H. Hayes, M. Gautier, Y. Chilliard, P. Martin, Gene 281(1), 53-61 (2001) DOI: $10.1016 / \mathrm{S} 0378-1119(01) 00822-8$

15. P.M. Kgwatalala, E.M. Ibeagha-Awemu, A.F. Mustafa, X. Zhao, Animal Genet. 40, 609-615 (2009)

16. J.F. Medrano, A. Johnson, E.J. Depeters, A. Islas, J. of Dairy Sci. 82, 71-75 (1999)

17. N. Safina, Sh. Shakirov, F. Zinnatova, Z. Fattakhova, E. Gaynutdinova, L. Shayakhmetova, Res. J. of Pharmac, Biolog. and Chem. Sci. 9(6), 2028-2031 (2018)

18. H. Ohsaki, A. Tanaka, S. Hoashi, S. Sasazaki, K. Oyama, M. Taniguchi, F. Mukai, H. Mannen, Animal Sci. J. 80, 225-232 (2009)

19. A. Dobrzyn, J.M. Ntambi, Prostaglandins, Leukotrienes and Essential Fatty Acids 73, 35-41 (2005)

20. M.T. Flowers, J.M. Ntambi, Current Opinion in Lipidology 19, 248-256 (2008)

21. GOST 32915-2014 (National Standard). Milk and milk products. Determination of fatty acid content by gas chromatography method (Moscow, 2015)

22. M. Taniguchi, T. Utsugi, K. Oyama, H. Mannen, M. Kobayashi, Y. Tanabe, A. Ogino, S. Tsuji, Mammalian Genome 14, 142-148 (2004)

23. M.V. Pozovnikova, G.N. Serdyuk, O.V. Tulinova, V.P. Terletskiy, N.V. Dementeva, O.V. Mitrofanova, Agricult. Biolog. 52(6), 1139-1147 (2017)

24. K. Inostroza, E. Scheuermann, N. Sepúlveda, Revista Colombiana de Ciencias Pecuarias 26, 263-269 (2013) 